\title{
Associations between cardiorespiratory fitness, motor competence, and adiposity in children
}

\section{Haapala, Eero A.}

2021-01

Haapala , E A , Gao , Y , Lintu , N , Väistö , J , Vanhala , A , Tompuri , T , Lakka , T A \&

Finni , T 2021 , ' Associations between cardiorespiratory fitness, motor competence, and

adiposity in children ' , Translational sports medicine , vol. 4 , no. 1, pp. 56-64 . https://doi.org/10.1002/tsm2.198

http://hdl.handle.net/10138/334831

https://doi.org/10.1002/tsm2.198

publishedVersion

Downloaded from Helda, University of Helsinki institutional repository.

This is an electronic reprint of the original article.

This reprint may differ from the original in pagination and typographic detail.

Please cite the original version. 


\title{
Associations between cardiorespiratory fitness, motor competence, and adiposity in children
}

\author{
Eero A. Haapala ${ }^{1,2}$ (D) | Ying Gao ${ }^{1,3} \mid$ Niina Lintu $^{2}$ | Juuso Väistö ${ }^{2}$ (i) | \\ Anssi Vanhala $^{1,4}$ | Tuomo Tompuri ${ }^{2,5}$ | Timo A. Lakka ${ }^{2,5,6}$ | Taija Finni $^{1}$ (iC)
}

${ }^{1}$ Faculty of Sport and Health Sciences, University of Jyväskylä, Jyväskylä, Finland

${ }^{2}$ Institute of Biomedicine, School of Medicine, University of Eastern Finland, Kuopio, Finland

${ }^{3}$ Department of Sports Science, College of Education, Zhejiang University, Hangzhou, China

${ }^{4}$ Department of Education, Faculty of Educational Sciences, University of Helsinki, Helsinki, Finland

${ }^{5}$ Department of Clinical Physiology and Nuclear Medicine, Kuopio University Hospital, Kuopio, Finland

${ }^{6}$ Kuopio Research Institute of Exercise Medicine, Kuopio, Finland

\section{Correspondence}

Eero A. Haapala, Faculty of Sport and Health Sciences, University of Jyväskylä, PO Box 35, FI-40014 Jyväskylä, Finland. Email: eero.a.haapala@jyu.fi

\section{Funding information}

Yrjö Jahnssonin Säätiö; Lastentautien Tutkimussäätiö; City of Kuopio; Sitra; Juho Vainion Säätiö; Diabetestutkimussäätiö; Sydäntutkimussäätiö; Paavo Nurmen Säätiö; Sosiaali- ja Terveysministeriö; Opetus- ja Kulttuuriministeriö, Grant/ Award Number: OKM/59/626/2016; Kela; Suomen Kulttuurirahasto; Research Committee of the Kuopio University Hospital Catchment Area

\begin{abstract}
We investigated the associations of motor competence (MC) with peak oxygen uptake $\left(\mathrm{VO}_{2 \text { peak }}\right)$, peak power output $\left(\mathrm{W}_{\text {max }}\right)$, and body fat percentage $(\mathrm{BF} \%)$ and whether measures of cardiorespiratory fitness (CRF) modify the associations between MC and BF\%. Altogether, 35 children (aged 7-11 years) in the CHIPASE Study and 297 in PANIC Study (aged 9-11 years) participated in the study. MC was assessed using KTK and modified Eurofit tests. $\mathrm{VO}_{2 \text { peak }}$ and $\mathrm{W}_{\text {max }}$ were measured by maximal exercise test on a cycle ergometer and scaled by lean mass (LM) or body mass (BM). BF\% was assessed either by bioimpedance (CHIPASE) or DXA (PANIC). MC was not associated with $\mathrm{VO}_{2 \text { peak }} / \mathrm{LM}$ (standardized regression coefficient $\beta=0.073-0.188, P>.083)$. $\mathrm{VO}_{2 \text { peak }} / \mathrm{BM}$ and $\mathrm{W}_{\max } / \mathrm{LM}$ and $\mathrm{BM}$ were positively associated with MC $(\beta=0.158-0.610, P<.05)$. $\mathrm{MC}(\beta=-0.186$ to -0.665 , $P<.01)$, but not $\mathrm{VO}_{2 \text { peak }} / \mathrm{LM}(\beta=-0.169-0.035, P>.381)$, was inversely associated with $\mathrm{BF} \%$. Furthermore, the associations of $\mathrm{MC}$ with $\mathrm{BF} \%$ were not modified by CRF. These results suggest that the positive associations between MC and CRF scaled by BM are a function of adiposity and not peak aerobic power and that CRF is not modifying factor in the associations of $\mathrm{MC}$ and $\mathrm{BF} \%$.
\end{abstract}

\section{K E Y W O R D S}

children, fitness, KTK, motor skills, obesity

\section{INTRODUCTION}

The prevalence of overweight and obesity has increased during the past three decades. ${ }^{1,2}$ Some evidence also suggests that motor competence (MC) and cardiorespiratory

Timo A. Lakka and Finni shared last authorship. fitness (CRF) have declined making the current generation of children less able and fit to participate in various physical and daily life activities than previous generations. ${ }^{3,4}$ These changes in MC and CRF in children have been suggested to lead to a negative circle leading to an increased risk of overweight and obesity. ${ }^{5}$ Nevertheless, variable methods used to assess CRF and inappropriate scaling of the measures of CRF 
may have obscured our understanding on the associations between MC, CRF, and adiposity.

Motor competence has been inversely associated with body mass index and body fat percentage (BF\%) among children in cross-sectional and longitudinal studies. ${ }^{6-9}$ Similarly, $\mathrm{MC}$ has been positively associated with $\mathrm{CRF}^{6}$ and it has been suggested that CRF lies in the causal pathway mediating the association between MC and overweight and obesity possibly through physical activity in children. ${ }^{5,10}$ However, the evidence on the positive associations between MC and CRF is mainly based on 20-m shuttle run test as a measure of CRF. ${ }^{11}$ Several studies have demonstrated that $\mathrm{VO}_{2 \text { peak }}$ explains less than $50 \%$ of the $20-\mathrm{m}$ shuttle run test performance ${ }^{12}$ limiting the validity of previous studies on the associations between $\mathrm{CRF}$ and $\mathrm{MC}^{13}$. Furthermore, some studies have showed a positive association between directly measured peak oxygen uptake $\left(\mathrm{VO}_{2 \text { peak }}\right)$, "a gold standard" in measuring CRF, scaled by body mass (BM) and MC. ${ }^{13,14}$ Lima et al also found that $\mathrm{VO}_{2 \text { peak }}$ scaled by BM mediated the associations of $\mathrm{MC}$ and physical activity with adiposity in their 7-year follow-up study suggesting that $\mathrm{VO}_{2 \text { peak }}$ could be an important factor influencing the associations between MC and adiposity. ${ }^{10}$ Nevertheless, scaling $\mathrm{VO}_{2 \text { peak }}$ by BM lacks physiological and statistical rationale and it does not remove the effect of body size and composition on CRF. ${ }^{15-17} \mathrm{BM}$ includes also fat mass that does not contribute to $\mathrm{VO}_{2 \text { peak }}$ or determinants of $\mathrm{VO}_{2 \text { peak }}$ and therefore underestimates CRF in heavier individuals irrespective of their physiological cardiorespiratory capacity. ${ }^{15-17}$

$\mathrm{VO}_{2 \text { peak }}$ depends on the capacity of cardiovascular system to deliver oxygenated blood to the working muscle and the ability of muscle tissue to utilize oxygen to support mechanical work. ${ }^{18}$ Maximal cardiac output has been found to be the strongest determinant of $\mathrm{VO}_{2 \text { peak }}$ during exercise. ${ }^{19,20}$ Muscle mass, that is an active tissue during exercise, is the main driver of absolute cardiac output and $\mathrm{VO}_{2 \text { peak, }}{ }^{21}$ while fat mass, that is included in $\mathrm{BM}$, does not contribute to cardiac output or $\mathrm{VO}_{2 \text { peak }} \cdot{ }^{17}$ Therefore, $\mathrm{VO}_{2 \text { peak }}$ scaled by lean mass (LM) using log-linear allometric modeling stands for the most appropriate measure of $\mathrm{CRF}^{22}$ Furthermore, peak power output $\left(\mathrm{W}_{\max }\right)$ achieved in cycle ergometer test, which is an indirect laboratory measure of CRF, has been used as an alternative measure of CRF. While $\mathrm{W}_{\max }$ has been suggested to serve a feasible indirect alternative to $\mathrm{VO}_{2 \text { peak, }}{ }^{23} \mathrm{~W}_{\text {max }}$ does not describe only peak aerobic power but is supported by anaerobic metabolism and the ability to recruit and more fully use higher threshold motor units. ${ }^{24}$ However, there are no previous studies comparing the associations of $\mathrm{VO}_{2 \text { peak }}$ and $\mathrm{W}_{\max }$ with $\mathrm{MC}$ and adiposity in children.

Previous studies have failed to provide valid information on the associations between $\mathrm{MC}$ and $\mathrm{VO}_{2 \text { peak }}$ and whether $\mathrm{VO}_{2 \text { peak }}$ modifies the magnitude of the associations between $\mathrm{MC}$ and adiposity in children. Therefore, using two separate data sets, we (a) investigated the associations of $\mathrm{VO}_{2 \text { peak }}$ and
$\mathrm{W}_{\text {max }}$ scaled by LM and BM with MC, (b) studied the associations between the measures of $\mathrm{CRF}$ and $\mathrm{BF} \%$, (c) explored the associations of $\mathrm{MC}$ with $\mathrm{BF} \%$, and (d) investigated whether the associations between $\mathrm{MC}$ and $\mathrm{BF} \%$ are explained by CRF.

\section{2 | METHODS}

\subsection{Study design and study populations}

The present cross-sectional data were derived from two separate studies conducted in Finland: The Children's Physical Activity Spectrum (CHIPASE) ${ }^{25}$ Study and the 2-year follow-up assessments of the Physical Activity and Nutrition in Children (PANIC) Study. ${ }^{26}$ The CHIPASE Study was designed to study the accuracy of different methods identify sedentary behavior and physical activity and their variability in 7- to 11 -year-old children. ${ }^{25}$ Altogether, 35 children were recruited from the schools in the City of Jyväskylä. The PANIC Study was physical activity and dietary intervention which continues as a follow-up study in a population sample of children from the city of Kuopio, Finland. Altogether, 440 children ( $86 \%$ of those participating in baseline examinations) attended in the 2-year follow-up examinations. In the present analyses, we used 2-year follow-up data of the PANIC Study because $\mathrm{VO}_{\text {2peak }}$ was assessed only at the follow-up assessments. Complete data on variables used in the analyses on the associations of $\mathrm{VO}_{2 \text { peak }}, \mathrm{MC}$, and $\mathrm{BF} \%$ at 2-year follow-up were available for 297 children (152 boys, 145 girls). Children who were included in the present analyses had a better $50-\mathrm{m}$ shuttle run test time than those who were excluded from the analyses $(P=.015)$, but there were no other differences in the participant characteristics between those who were included and those who were excluded. The study protocol of the CHIPASE Study was approved by the Research Ethics Committee of University of Jyväskylä and that of the PANIC Study was approved by the Research Ethics Committee of the Hospital District of Northern Savo. Both children and their parents gave their written informed consent.

\subsection{Assessment of body size and composition}

In the CHIPASE Study, body weight, LM, fat mass, and BF\% were assessed after an overnight fast by a calibrated InBody ${ }^{\circledR}$ 770 bioelectrical impedance device (Biospace, Seoul, South Korea). In the PANIC Study, body weight was measured after 12 hours fast by InBody ${ }^{\circledR} 720$ bioelectrical impedance device (Biospace) and total fat mass, $\mathrm{BF} \%$, and $\mathrm{LM}$ were measured by the Lunar ${ }^{\circledR}$ dual-energy X-ray absorptiometry (GE Medical Systems) using standardized protocols. ${ }^{27}$ Stature 
was measured the children standing head in the Frankfurt plane without shoes using a wall-mounted stadiometer to accuracy of $0.1 \mathrm{~cm}$.

\section{3 $\mid$ Assessment of MC}

In the CHIPASE Study, MC was assessed by the Körperkoordination test für Kinder (KTK). ${ }^{28}$ During the assessment, children were asked to (a) walk backwards on balance beams with decreasing widths of $6.0 \mathrm{~cm}, 4.5 \mathrm{~cm}$, and $3.0 \mathrm{~cm}$, (b) hop for height on one foot at a time, over a pile of soft mattresses (width $60 \mathrm{~cm}$; depth $20 \mathrm{~cm}$; height $5 \mathrm{~cm}$ each) with increasing height after each successful attempt, (c) jump sideways from side to side over a thin wooden lath $(60 \times 4 \times 2 \mathrm{~cm})$ on the jumping base $(100 \times 60 \mathrm{~cm})$, and (d) move sideways with wooden plates (size $25 \times 25 \mathrm{~cm}$; height $5.7 \mathrm{~cm}$ ) without stepping out as quickly as possible for 20 seconds. In each subtest, higher score indicates better MC. Raw scores from these tasks were used in the analyses.

In the PANIC Study, MC was assessed using 50-m change of direction shuttle run test, standing long jump test, modified flamingo balance, and the box and block test. ${ }^{29}$ In the $50-\mathrm{m}$ shuttle run test, the children were asked to run $5 \mathrm{~m}$ from a starting line to another line as fast as possible, to turn on the line, to run back to the starting line, and to continue until five shuttles were completed. The test score was the running time in seconds, with a longer time indicating a poorer performance. In the standing long jump test, the children were asked to stand the feet next to each other, to jump as far as possible, and to land on both feet. The test score was the best result of three attempts in centimeters. In the modified flamingo balance test, the children were asked to stand barefoot on one self-chosen leg with eyes closed for $30 \mathrm{~s}$. The test score was the number of floor touches with a free foot or eye openings during $30 \mathrm{~s}$, higher number of floor touches and eye openings indicating poorer static balance. In the box and block test, the children were asked to pick up small wooden cubes $(2.5 \mathrm{~cm}$ per side) one by one with the dominant hand from one side of a wooden box $(53.7 \mathrm{~cm} \times 25.4 \mathrm{~cm} \times 8 \mathrm{~cm})$ and to move as many cubes as possible to the other side of the box during $60 \mathrm{~s}$ and to repeat the same task with the non-dominant hand. The test score was the total number of cubes moved to the other side of the box during 120 seconds, a smaller number of cubes moved indicating poorer manual dexterity.

\subsection{Assessment of CRF}

In the CHIPASE and the PANIC Study, CRF was assessed using a maximal ramp exercise test with an electromagnetically braked Ergoline cycle ergometer (Ergoselect $200 \mathrm{~K}$; Ergoline). In the CHIPASE Study, the exercise protocol included 3-minute warm-up at 20 Watts (W), an exercise period until exhaustion with a workload increase of $1 \mathrm{~W}$ every 3,4 , or 6 seconds depending on the stature of a child, ${ }^{30}$ and a 2-3 minute cooling down period without resistance. In the PANIC Study, the exercise test protocol included a 3-minute warm-up period at $5 \mathrm{~W}$, a 1-minute steady-state period at $20 \mathrm{~W}$, an exercise period with a workload increase of $1 \mathrm{~W}$ every $6 \mathrm{~s}$ until exhaustion and a 4-minute coolingdown period at $5 \mathrm{~W} .^{31}$

Respiratory gases were collected using pediatric masks (Hans-Rudolph) during the test. The respiratory gas analyzers (CHIPASE: Jaeger Oxygon Mobile; PANIC: Jaeger Oxycon Pro) were calibrated according to the manufacturer's instructions. Respiratory gases were measured directly by the breath-by-breath method from the 2-2.5-minute anticipatory period sitting on the ergometer to the post-exercise rest and were averaged over consecutive 15 -s periods. The peak values of $\mathrm{VO}_{2}$, respiratory exchange ratio (RER), and $V_{E}$ were defined as the highest 15 -s average value recorded during the last minute of the test. Acknowledging the limitations of secondary indicators of true maximal oxygen uptake in children ${ }^{32}$ and the lack of supramaximal validation test in the present studies, the exercise tests were considered maximal if primary and secondary physiological criteria indicated maximal effort and maximal cardiopulmonary capacity (eg, plateau in $\mathrm{VO}_{2}, \mathrm{RER} \geq 1.0$ ) and the exercise specialist supervising the test considered the test maximal. ${ }^{31}$

We scaled $\mathrm{VO}_{2 \text { peak }}$ by $\mathrm{LM}^{-1}$ because $\mathrm{VO}_{2 \text { peak }}(\beta=-0.097$ to $-0.075, P>.200)$ and $\mathrm{W}_{\max }(\beta=-0.069$ to 0.228 , $P>$.202) scaled by $\mathrm{LM}^{-1}$ were not statistically significantly associated with LM suggesting the validity in scaling of CRF in both studies. We also scaled $\mathrm{VO}_{2 \text { peak }}$ and $\mathrm{W}_{\text {max }}$ by $\mathrm{BM}^{-1}$ to investigate the associations of $\mathrm{CRF}$ with $\mathrm{MC}$ and $\mathrm{BF} \%$ with conventional measure of CRF.

\section{5 | Other assessments}

Maturity offset reflecting years from peak height velocity was used as an indicator of maturity. It was calculated separately for boys and girls using equations provided by Moore et al. $^{33}$

\section{6 | Statistical methods}

We performed all data analyses using SPSS Statistics, Version 24.0 (IBM Corp.). Basic characteristics between boys and girls were compared using the Student's $t$ test, the Mann-Whitney U test, or the chi square-test. To reduce the 
number of $\mathrm{MC}$ variables, we performed principal component analyses to extract different $\mathrm{MC}$ components. After principal component analyses, we computed population specific MC $\mathrm{z}$-scores using the raw scorers from single MC tests. In the CHIPASE Study, all KTK variables loaded to same factor (0.245-0.304) explaining $78.3 \%$ of the variance and therefore we computed a total MC score from the $\mathrm{z}$-scores of the KTK subtest scores. Because balance assessed using walking backwards on a balance beam differs from other KTK tests as it is not time-dependent or jumping-related and it had the lowest correlation coefficient with other variables, we also analyzed the associations of balance $\mathrm{MC}$ with $\mathrm{CRF}$ and $\mathrm{BF} \%$ separately. In the PANIC Study, the first component explaining the highest proportion of variance $(43.8 \%)$ was heavily loaded by $50-\mathrm{m}$ shuttle run $(-0.897)$ and standing long jump (0.920). The second factor (27.8\%) had high loadings with flamingo balance (0.790) and box and block $(-0.761)$. Therefore, we created locomotor MC score from 50-m shuttle run test and standing long jump z-scores and balance and manual dexterity MC score from the modified flamingo balance and box and block test z-scores based on the principal component analysis. The associations between the measures of $\mathrm{CRF}$, the measures of $\mathrm{MC}$, and $\mathrm{BF} \%$ were analyzed using linear regression analyses adjusted for age and sex. Whether $\mathrm{VO}_{2 \text { peak }}$ or $\mathrm{W}_{\text {max }}$ scaled by $\mathrm{LM}^{-1}$ modify the magnitude of the association of $\mathrm{MC}$ with $\mathrm{BF} \%$ was investigated using the three-step hierarchical linear regression analyses adjusted for age and sex. BF\% was included as the depended variable, and age and sex were included as covariates at the first step. At the second step, MC was included in the model as the primary independent variable. Finally, $\mathrm{VO}_{2 \text { peak }}$ or $\mathrm{W}_{\max }$ scaled by $\mathrm{LM}^{-1}$ was included in the model at step 3 as possible modifying factor. We found no evidence that sex modified the associations between the measures of CRF and the measures of MC in the PANIC Study, and therefore, we performed these analyses girls and boys combined. We found that sex modified the associations of BF\% with balance and manual dexterity MC score ( $P=.038$ for interaction), and therefore, we analyzed the association of $\mathrm{BF} \%$ with balance and manual dexterity MC score separately for boys and girls. Statistical power was estimated using the G*Power software. ${ }^{34,35} 395$ to 55 observations were needed to observe small to medium effect size $\left(\mathrm{f}^{2}\right)$ and 55 to 25 observations to observe medium to large effect sizes in the linear regression analyses.

\section{3 | RESULTS}

\section{1 | Basic characteristics}

Boys had lower maturity offset, more LM, and higher absolute $\mathrm{VO}_{2 \text { peak }}$ and $\mathrm{W}_{\max }$ than girls in both studies (Table 1). In the PANIC Study, boys also had less fat mass, lower BF\%, and higher $\mathrm{LM}$ and $\mathrm{BM}$ proportional $\mathrm{VO}_{2 \text { peak }}$ and $\mathrm{W}_{\max }$. Boys also had faster 50-m shuttle run and better standing long jump performance but poorer box and block and flamingo balance test performance than girls.

\subsection{Associations of CRF with MC}

$\mathrm{VO}_{2 \text { peak }}$ scaled by $\mathrm{LM}^{-1}$ was not associated with $\mathrm{MC}$ in neither of the studies (Table 2). In the CHIPASE Study, $\mathrm{VO}_{2 \text { peak }}$ scaled by $\mathrm{BM}^{-1}$ was positively associated with total $\mathrm{MC}$ and balance MC. In the PANIC Study, $\mathrm{VO}_{2 \text { peak }}$ scaled by $\mathrm{BM}^{-1}$ was positively associated with locomotor MC and balance and manual dexterity MC.

In the CHIPASE Study, $\mathrm{W}_{\max }$ scaled by $\mathrm{LM}^{-1}$ and $\mathrm{BM}^{-1}$ was positively associated with total MC and balance MC (Table 2). In the PANIC Study, $\mathrm{W}_{\max }$ scaled by $\mathrm{LM}^{-1}$ and $\mathrm{BM}^{-1}$ was positively associated with locomotor $\mathrm{MC}$ and balance and manual dexterity MC.

\section{3 | Associations of CRF with body fat percentage}

In the CHIPASE Study, $\mathrm{VO}_{2 \text { peak }}$ and $\mathrm{W}_{\text {max }}$ scaled by $\mathrm{LM}^{-1}$ were not associated with BF\% (Table 2). In the PANIC Study, $\mathrm{VO}_{2 \text { peak }}$ scaled by $\mathrm{LM}^{-1}$ was not associated with $\mathrm{BF} \%$. $\mathrm{VO}_{2 \text { peak }}$ and $\mathrm{W}_{\text {max }}$ scaled by $\mathrm{BM}^{-1}$ were inversely associated with BF\% in both studies. Furthermore, $\mathrm{W}_{\max }$ scaled by $\mathrm{LM}^{-1}$ was inversely associated with BF\% in the PANIC Study.

\subsection{Associations of MC with body fat percentage}

In the CHIPASE Study, total MC and balance MC were inversely associated with BF\% (Table 2). In the PANIC Study, locomotor and balance and manual dexterity $\mathrm{MC}$ were inversely associated with $\mathrm{BF} \%$. However, balance and manual dexterity $\mathrm{MC}$ were inversely associated with $\mathrm{BF} \%$ in boys $(\beta=-0.265, P=.001)$ but not in girls $(\beta=-0.035, P=.683)$.

\section{5 | Modifying effects of CRF in the associations of MC with body fat percentage}

In the CHIPASE Study, total MC and balance MC were inversely associated with $\mathrm{BF} \%$ (Table 2 ) and these associations remained statistically significant $(\beta=-0.703$ to -0.521 , $P \leq .02$ ) after including $\mathrm{VO}_{2 \text { peak }}$ or $\mathrm{W}_{\text {max }}$ scaled by $\mathrm{LM}^{-1}$ to the regression model.

In the PANIC Study, locomotor MC was inversely associated with $\mathrm{BF} \%$. This association remained $\operatorname{similar}(\beta=-0.527$ 


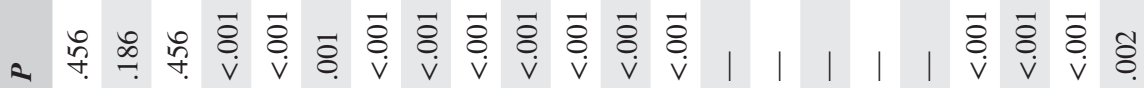

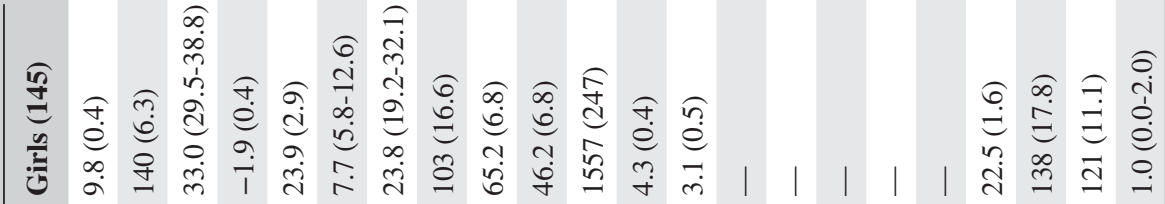

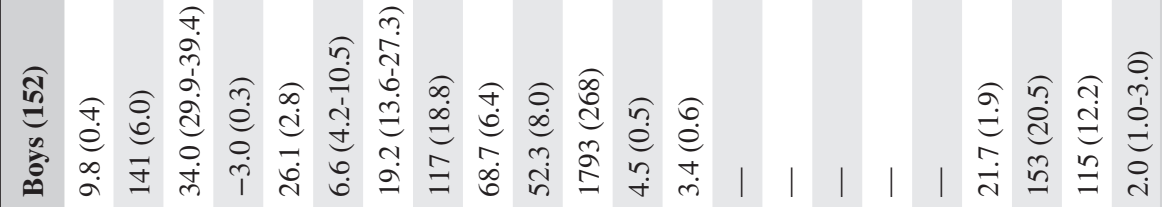

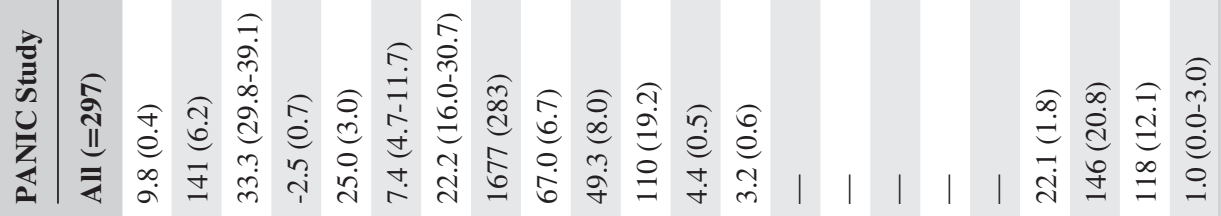

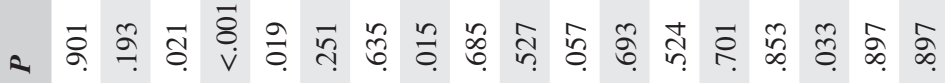

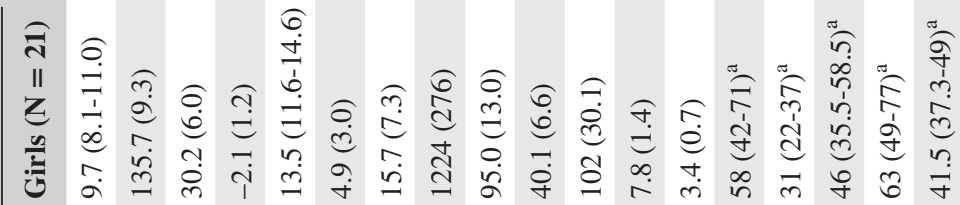

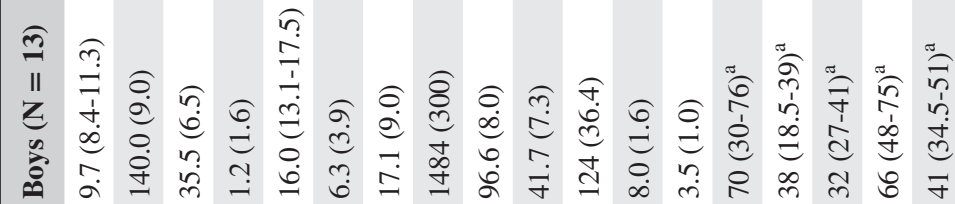

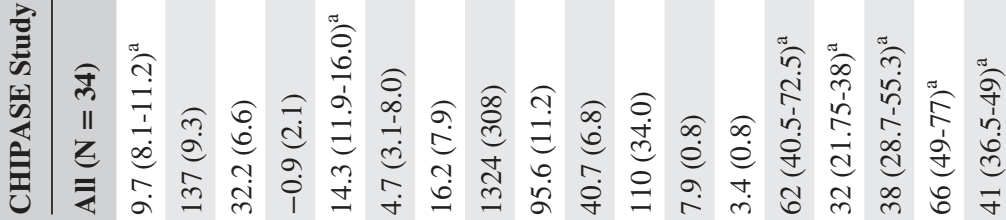




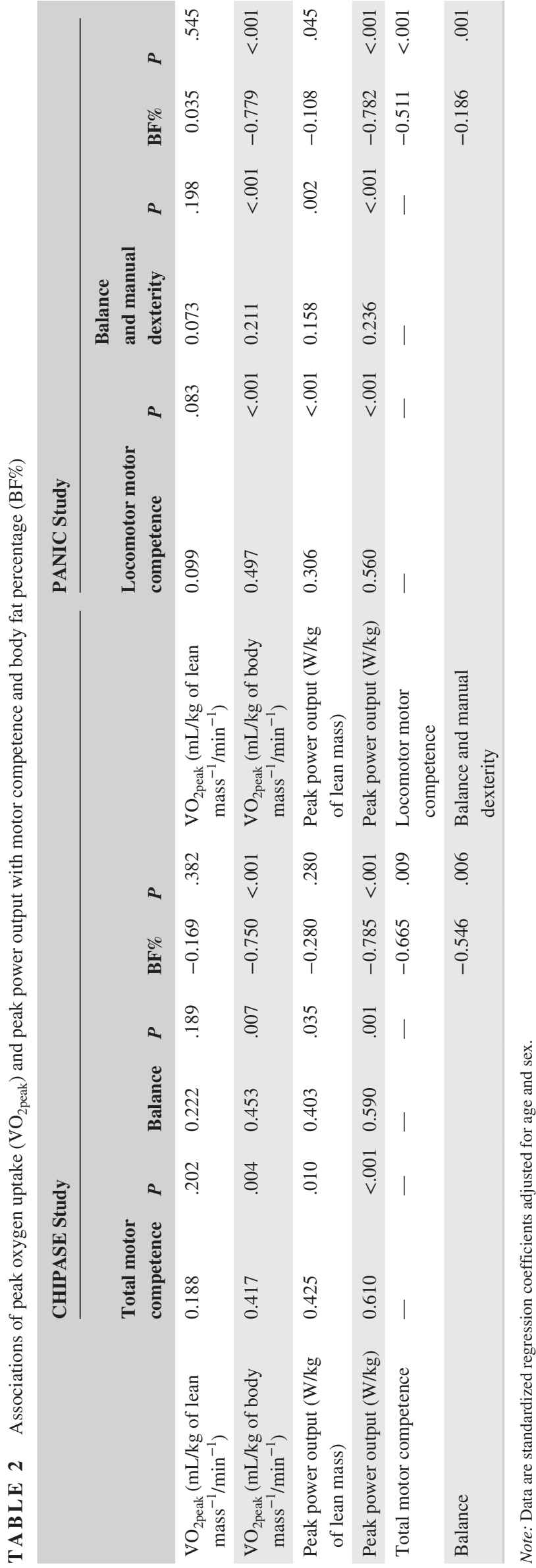

to $-0.511, P<.001$ ) when $\mathrm{VO}_{2 \text { peak }}$ or $\mathrm{W}_{\text {max }}$ scaled by $\mathrm{LM}^{-1}$ was included to the regression model. Similarly, balance and manual dexterity MC were inversely associated with $\mathrm{BF} \%$ and including $\mathrm{VO}_{2 \text { peak }}$ or $\mathrm{W}_{\text {max }}$ scaled by $\mathrm{LM}^{-1}$ had no effect on the magnitude of the association between balance and manual dexterity $\mathrm{MC}$ and $\mathrm{BF} \%(\beta=-0.190$ to -0.177 , $P=.002$ after including $\mathrm{VO}_{2 \text { peak }}$ or $\mathrm{W}_{\text {max }}$ scaled by $\mathrm{LM}^{-1}$ to the model).

The inverse association between $\mathrm{W}_{\text {max }}$ scaled by $\mathrm{LM}^{-1}$ and $\mathrm{BF} \%$ was no longer statistically significant when locomotor MC $(\beta=0.053, P=.283)$ or balance and manual dexterity MC ( $\beta=-0.081, P=.133)$ was entered into the model at the same time.

\section{4 | DISCUSSION}

We showed, using two separate data sets, that children with lower and higher levels of MC had similar levels of CRF scaled by LM, whereas children with poorer MC had lower levels of CRF scaled by BM. We also showed that MC, but not CRF, was inversely associated with BF\%. Furthermore, we found that the associations of MC with $\mathrm{BF} \%$ were not explained by CRF. These results suggest that the positive association between MC and CRF scaled by BM is a function of adiposity rather than peak aerobic power and that CRF is not a modifying factor in the associations between $\mathrm{MC}$ and $\mathrm{BF} \%$.

Our findings do not support previous findings on the positive associations of MC and CRF in children. ${ }^{6} \mathrm{~A}$ reason for these divergent results is that previous studies have used body size and composition confounded measures of $\mathrm{CRF},{ }^{16,18,22,31}$ such as $20-\mathrm{m}$ shuttle run test ${ }^{6}$ or $\mathrm{VO}_{2 \text { peak }}$ scaled by $\mathrm{BM},{ }^{13,14}$ while we utilized $\mathrm{VO}_{2 \text { peak }}$ scaled by LM that is the preferred method to normalize CRF for body size and composition. ${ }^{22}$ Furthermore, we found a weak and statistically insignificant relationship of $\mathrm{VO}_{2 \text { peak }}$ scaled by $\mathrm{LM}$ to $\mathrm{BF} \%$ while we observed a strong inverse association between $\mathrm{VO}_{2 \text { peak }}$ scaled by $\mathrm{BM}$ and $\mathrm{BF} \%$. These findings agree with previous studies and physiological observations that LM is the strongest determinant of $\mathrm{VO}_{2 \text { peak }}{ }^{21}$ and that fat mass does not contribute to $\mathrm{VO}_{2 \text { peak. }}{ }^{17}$

In line with the previous studies, ${ }^{6}$ we demonstrated an inverse association between $\mathrm{MC}$ and $\mathrm{BF} \%$. These findings suggest that $\mathrm{MC}$ is important determinant of body composition and that many tests used to assess MC are highly dependent on $\mathrm{BF} \%$. Therefore, it is not surprising that $\mathrm{VO}_{2 \text { peak }}$, which is not influence by fat mass, does not play a role in the associations between $\mathrm{MC}$ and $\mathrm{BF} \%$. Nevertheless, we also showed that higher $\mathrm{VO}_{2 \text { peak }}$ scaled by $\mathrm{BM}$ was associated with better $\mathrm{MC}$ and lower $\mathrm{BF} \%$ suggesting that the previous observations on the positive associations of MC with $\mathrm{CRF}$ and the modifying role of $\mathrm{CRF}$ in the associations between $\mathrm{MC}$ and $\mathrm{BF} \%$ are largely influenced by body composition rather than peak aerobic power. $^{18,22}$ 
Although we found weak and statistically insignificant association between $\mathrm{VO}_{\text {2peak }}$ scaled by $\mathrm{LM}, \mathrm{MC}$, and $\mathrm{BF} \%$, we observed that $\mathrm{W}_{\max }$ scaled either by LM or BM was positively associated with MC. We also found a weak inverse association between $\mathrm{W}_{\max }$ scaled by $\mathrm{LM}$ and $\mathrm{BF} \%$ in the PANIC Study, which is in contrast to the results with $\mathrm{VO}_{2 \text { peak }}$. The reason for these partly contrasting findings between the measures of CRF may be that $\mathrm{VO}_{2 \text { peak }}$ is a measure of peak aerobic power reflecting the integrated ability of cardiorespiratory system and skeletal muscles to deliver and extracting oxygen for energy production supporting muscle activity during exercise and is mainly dependent on cardiac output, while $\mathrm{W}_{\max }$ requires both aerobic and anaerobic metabolism and is more dependent on neuromuscular characteristic than $\mathrm{VO}_{2 \text { peak. }}{ }^{24}$ The reasons for the negative association between $\mathrm{W}_{\max }$ and $\mathrm{BF} \%$ may be reduced muscle quality, ${ }^{36,37}$ impaired motor unit activation, ${ }^{38}$ and reduced nerve amplitude ${ }^{39}$ in children with higher BF\%. These factors together may limit the ability to produce power per muscle cross-sectional area in children with higher $\mathrm{BF} \%$ and therefore explain inverse association between $\mathrm{W}_{\max }$ and $\mathrm{BF} \%$. Furthermore, $\mathrm{MC}$ explained the inverse association between $\mathrm{W}_{\max }$ and $\mathrm{BF} \%$ suggesting that one reason for this association maybe poorer ability to coordinate the neuromuscular system in cooperative fashion during the exercise test. These results are supported by previous findings showing that $\mathrm{W}_{\max }$ is also a product of neuromuscular performance. ${ }^{40,41}$ Therefore, our results suggest that $\mathrm{VO}_{2 \text { peak }}$ and $\mathrm{W}_{\text {max }}$ should not be used interchangeably and the associations of different measures of CRF with MC should be interpreted cautiously.

The strengths of the present study include the use of two separate data set and valid and objective assessment of MC, $\mathrm{VO}_{2 \text { peak }}, \mathrm{W}_{\text {max }}$, and body composition. We also scaled the measures of CRF with LM instead on relying on traditional ratio scaling by BM. However, DXA, the reference method for body composition assessment, was not available in the CHIPASE Study. However, we utilized DXA in the PANIC Study to provide the best available evidence on the associations between $\mathrm{CRF}, \mathrm{MC}$, and adiposity. In addition, the measures of MC differed between the data sets and it would have been optimal to use the same methodology to allow direct comparison between studies. Nevertheless, the results were similar despite the different measures of MC strengthening the generalizability of our results. The sample size in the CHIPASE Study was also relatively small, and within this study, the associations were statistically significant mostly with large effect sizes. Therefore, further studies to investigate the associations between $\mathrm{CRF}, \mathrm{MC}$, and adiposity in larger populations are still warranted. Furthermore, it is possible that other measurers of fitness, such as muscle strength or anaerobic capacity, modify or mediate the associations between $\mathrm{MC}$ and $\mathrm{BF} \%$. However, we did not have comparable measures of muscle strength or anaerobic capacity in the
CHIPASE Study and the PANIC Study. Finally, we did not include physical activity into our analyses although it is an important determinant of adiposity and $\mathrm{MC}$ in children. ${ }^{5,6,8,42}$ While physical activity has been considered important factor mediating or moderating the associations between CRF, adiposity, and MC, we did not include physical activity into the present analyses because the current methodology used to assess physical activity and define cut-offs for light, moderate, and vigorous intensity physical activity may lead to large errors in the volume of physical activity at different intensities $^{43-45}$ and underestimate the true volume and intensity of physical activity especially in unfit and overweight or obese individuals. ${ }^{44,46}$ Therefore, including physical activity into our analyses would increase uncertainty to our results.

In conclusion, $\mathrm{MC}$ was not associated with $\mathrm{VO}_{2 \text { peak }}$ in children whereas children with better MC also had higher $\mathrm{W}_{\max }$. Furthermore, CRF did not modify the association between $\mathrm{MC}$ and $\mathrm{BF} \%$. Therefore, different measures of CRF should not be used interchangeably and the interpretation of results should be adjusted accordingly. Our results highlight the need for further studies investigating the moderators and mediators of the association of $\mathrm{MC}$ and $\mathrm{BF} \%$, such as individually determined physical activity intensity and volume, sedentary behavior, muscle strength and power, and other components of physical fitness instead of CRF.

\section{5 | PERSPECTIVES}

Several cross-sectional and some longitudinal studies have demonstrated positive associations between MC and CRF and suggested that CRF mediate the associations of MC with BF\% ${ }^{6,13}$ However, most of these previous studies have used methodology that prevents any firm conclusions on the role of peak aerobic power in $\mathrm{MC}$ and $\mathrm{BF} \%$. Our results suggest that the previous observations on the positive associations of $\mathrm{MC}$ with CRF and the modifying role of CRF in the associations between $\mathrm{MC}$ and $\mathrm{BF} \%$ are largely influenced by body composition rather than peak aerobic power. Thus, to put our findings in perspective, our findings indicate that there are no remarkable differences in the functions of the cardiorespiratory system defined as $\mathrm{VO}_{2 \text { peak }}$ between children with higher or lower levels of $\mathrm{MC}$ and adiposity. Therefore, our findings suggest that role of $\mathrm{CRF}$ in $\mathrm{MC}$ and $\mathrm{BF} \%$ may have been overestimated and further studies with appropriate assessment and interpretation of $\mathrm{CRF}$ in relation to $\mathrm{MC}$ and $\mathrm{BF} \%$ are highly warranted.

\section{ACKNOWLEDGEMENTS}

CHIPASE was funded by Ministry of Education and Culture (OKM/59/626/2016). YG was supported by the Finnish Cultural Foundation Regional fund (20052018). The PANIC Study has financially been supported by Ministry of Education and Culture of Finland, Ministry of Social Affairs and Health 
of Finland, Research Committee of the Kuopio University Hospital Catchment Area (State Research Funding), Finnish Innovation Fund Sitra, Social Insurance Institution of Finland, Finnish Cultural Foundation, Foundation for Paediatric Research, Diabetes Research Foundation in Finland, Finnish Foundation for Cardiovascular Research, Juho Vainio Foundation, Paavo Nurmi Foundation, Yrjö Jahnsson Foundation, and the city of Kuopio. Moreover, the PhD students and postdoctoral researchers of The PANIC Study have been supported by Program for Clinical Research and Program for Health Sciences of Doctoral School of University of Eastern Finland, Finnish Doctoral Programs in Public Health, Päivikki and Sakari Sohlberg Foundation, Paulo Foundation, Jalmari and Rauha Ahokas Foundation, Aarne and Aili Turunen Foundation, Finnish Medical Foundation, Jenny and Antti Wihuri Foundation, Kuopio Naturalists' Society, Olvi Foundation, and the city of Kuopio.

\section{ORCID}

Eero A. Haapala (D) https://orcid.org/0000-0001-5096-851X Juuso Väistö (D) https://orcid.org/0000-0001-7026-5934 Taija Finni (D) https://orcid.org/0000-0002-7697-2813

\section{REFERENCES}

1. Kautiainen S, Rimpelä A, Vikat A, Virtanen SM. Secular trends in overweight and obesity among Finnish adolescents in 1977-1999. Int J Obes. 2002;26(4):544-552.

2. Broyles S, Katzmarzyk PT, Srinivasan SR, et al. The pediatric obesity epidemic continues unabated in Bogalusa, Louisiana. Pediatrics. 2010;125(5):900-905.

3. Tomkinson GR, Lang JJ, Tremblay MS. Temporal trends in the cardiorespiratory fitness of children and adolescents representing 19 high-income and upper middle-income countries between 1981 and 2014. Br J Sports Med. 2019;53(8):478-486.

4. Vandorpe B, Vandendriessche J, Lefevre $J$, et al. The KörperkoordinationsTest für Kinder: reference values and suitability for 6-12-year-old children in Flanders. Scand J Med Sci Sports. 2011;21(3):378-388.

5. Stodden D, Goodway J, Langendorfer S, et al. A developmental perspective on the role of motor skill competence in physical activity: an emergent relationship. Quest. 2008;60):290-306.

6. Robinson LE, Stodden DF, Barnett LM, et al. Motor competence and its effect on positive developmental trajectories of health. Sports Med. 2015;45(9):1273-1284.

7. D'Hondt E, Deforche B, Gentier I, et al. A longitudinal analysis of gross motor coordination in overweight and obese children versus normal-weight peers. Int J Obes. 2013;37(1):61-67.

8. Barnett LM, Lai SK, Veldman SLC, et al. Correlates of gross motor competence in children and adolescents: a systematic review and meta-analysis. Sports Med. 2016;46(11):1663-1688.

9. Slotte S, Sääkslahti A, Metsämuuronen J, Rintala P. Fundamental movement skill proficiency and body composition measured by dual energy X-ray absorptiometry in eight-year-old children. Early Child Dev Care. 2015;185(3):475-485.

10. Lima RA, Pfeiffer KA, Bugge A, Møller NC, Andersen LB, Stodden DF. Motor competence and cardiorespiratory fitness have greater influence on body fatness than physical activity across time. Scand J Med Sci Sports. 2017;27(12):1638-1647.

11. Cattuzzo MT, dos Santos HR, Ré AHN, et al. Motor competence and health related physical fitness in youth: a systematic review. $J$ Sci Med Sport. 2016;19(2):123-129.

12. Mayorga-Vega D, Aguilar-Soto P, Viciana J. Criterion-related validity of the 20-M shuttle run test for estimating cardiorespiratory fitness: a meta-analysis. J Sports Sci Med. 2015;14(3):536-547.

13. Lima RA, Bugge A, Ersbøll AK, Stodden DF, Andersen LB. The longitudinal relationship between motor competence and measures of fatness and fitness from childhood into adolescence. $J$ Pediatr (Rio J). 2019;95(4):482-488.

14. Lima RA, Pfeiffer K, Larsen LR, et al. Physical activity and motor competence present a positive reciprocal longitudinal relationship across childhood and early adolescence. J Phys Activity Health. 2017;14(6):440-447.

15. Tanner JM. Fallacy of per-weight and per-surface area standards, and their relation to spurious correlation. J Appl Physiol. 1949;2(1):1-15.

16. Welsman J, Armstrong N. Interpreting aerobic fitness in youth: the fallacy of ratio scaling. Pediatr Exerc Sci. 2019;31(2):184-190.

17. Goran M, Fields DA, Hunter GR, Herd SL, Weinsier RL. Total body fat does not influence maximal aerobic capacity. Int $J$ Obes. 2000;24(7):841-848.

18. Armstrong N, Welsman J. Clarity and confusion in the development of youth aerobic fitness. Front Physiol. 2019;10:979.

19. Mezzani A. Cardiopulmonary exercise testing: basics of methodology and measurements. Annals ATS. 2017;14(Suppl.1):S3-S11.

20. Takken T, Bongers BC, van Brussel M, Haapala EA, Hulzebos EHJ. Cardiopulmonary exercise testing in pediatrics. Annals ATS. 2017;14(Suppl.1):S123-S128.

21. Armstrong N, Welsman J. Sex-specific longitudinal modeling of youth peak oxygen uptake. Pediatr Exerc Sci. 2019;31(2):204-212.

22. Loftin M, Sothern M, Abe T, Bonis M. Expression of VO2peak in children and youth, with special reference to allometric scaling. Sports Med. 2016;46(10):1451-1460.

23. Dencker M, Thorsson O, Karlsson MK, Lindén C, Wollmer P, Andersen LB. Maximal oxygen uptake versus maximal power output in children. J Sports Sci. 2008;26(13):1397-1402.

24. Rowland TW. American College of Sports Medicine, Medicines (NASPEM) NAS for PE. Cardiopulmonary Exercise Testing in Children and Adolescents. Windsor: Human Kinetics, Inc.; 2017.

25. Gao Y, Haapala EA, Vanhala A, et al. Sedentary thresholds for accelerometry-based mean amplitude deviation and electromyography amplitude in 7-11 years old children. Front Physiol. 2019;10:7-11.

26. Eloranta AM, Lindi V, Schwab U, et al. Dietary factors and their associations with socioeconomic background in Finnish girls and boys 6-8 years of age: the PANIC Study. Eur J Clin Nutr. 2011;65(11):1211-1218.

27. Tompuri TT, Lakka TA, Hakulinen M, et al. Assessment of body composition by dual-energy X-ray absorptiometry, bioimpedance analysis and anthropometrics in children: the Physical Activity and Nutrition in Children study. Clin Physiol Funct Imaging. 2015;35:21-33.

28. Kiphard EJ, Schilling F. Körperkoordinationstest für Kinder: KTK. Göttingen, Germany: Beltz-Test; 2007.

29. Haapala EA, Lintu N, Väistö J, et al. Associations of physical performance and adiposity with cognition in children. Med Sci Sports Exerc. 2015;47:2166-2174. 
30. Godfrey S, Davies CTM, Wozniak E, Barnes CA. Cardiorespiratory response to exercise in normal children. Clin Sci. 1971;40(5):419-431.

31. Tompuri T, Lintu N, Savonen K, et al. Measures of cardiorespiratory fitness in relation to measures of body size and composition among children. Clin Physiol Funct Imaging. 2015;35(6):469-477.

32. Sansum KM, Weston ME, Bond B, et al. Validity of the supramaximal test to verify maximal oxygen uptake in children and adolescents. Pediatr Exerc Sci. 2019;31(2):213-222.

33. Moore S, McKay H, Macdonald H, et al. Enhancing a somatic maturity prediction model. Med Sci Sports Exerc. 2014;47.

34. Faul F, Erdfelder E, Lang A-G, Buchner A. G*Power 3: A flexible statistical power analysis program for the social, behavioral, and biomedical sciences. Behav Res Methods. 2007;39(2):175-191.

35. Faul F, Erdfelder E, Buchner A, Lang A-G. Statistical power analyses using $\mathrm{G}^{*}$ Power 3.1: Tests for correlation and regression analyses. Behav Res Methods. 2009;41(4):1149-1160.

36. Peterson MD, Liu D, Gordish-Dressman H, et al. Adiposity attenuates muscle quality and the adaptive response to resistance exercise in non-obese, healthy adults. Int J Obes. 2011;35(8):1095-1103.

37. Moore AZ, Caturegli G, Metter EJ, et al. Difference in muscle quality over the adult life span and biological correlates in the Baltimore Longitudinal Study of Aging. J Am Ger Soc. 2014;62(2):230-236.

38. Blimkie CJR, Sale DG, Bar-Or O. Voluntary strength, evoked twitch contractile properties and motor unit activation of knee extensors in obese and non-obese adolescent males. Eur J Appl Physiol. 1990;61(3):313-318.

39. Buschbacher RM. Body mass index effect on common nerve conduction study measurements. Muscle Nerve. 1998;21(11):1398-1404.

40. Korff T, Hunter EL, Martin JC. Muscular and non-muscular contributions to maximum power cycling in children and adults: implications for developmental motor control. $K$ Exp Biol. 2009;212(5):599-603.

41. Van Praagh E, Doré E. Short-term muscle power during growth and maturation. Sports Med. 2002;32(11):701-728.

42. Collings PJ, Westgate K, Väistö J, et al. Cross-sectional associations of objectively-measured physical activity and sedentary time with body composition and cardiorespiratory fitness in mid-childhood: The PANIC Study. Sports Med. 2017;47(4):769-780.

43. Haapala EA, Gao Y, Vanhala A, Rantalainen T, Finni T. Validity of traditional physical activity intensity calibration methods and the feasibility of self-paced walking and running on individualised calibration of physical activity intensity in children. Sci Rep. 2020;10(1):11031.

44. Kujala UM, Pietilä J, Myllymäki T, et al. Physical activity: absolute intensity versus relative-to-fitness-level volumes. Med Sci Sports Exerc. 2017;49(3):474.

45. Gil-Rey E, Maldonado-Martin S, Palacios-Samper N, Gorostiaga EM. Objectively measured absolute and relative physical activity intensity levels in postmenopausal women. Eur J Sport Sci. 2019;19:539-548.

46. Gil-Rey E, Maldonado-Martin S, Gorostiaga E. Individualized accelerometer activity cut-points for the measurement of relative physical activity intensity levels. Res Q Exerc Sport. 2019;90:1-9.

How to cite this article: Haapala EA, Gao Y, Lintu $\mathrm{N}$, et al. Associations between cardiorespiratory fitness, motor competence, and adiposity in children. Transl Sports Med. 2021;4:56-64. https://doi. org/10.1002/tsm2.198 